\title{
MAOA promoter methylation and susceptibility to carotid atherosclerosis: role of familial factors in a monozygotic twin sample
}

\author{
Jinying Zhao ${ }^{*}$, Christopher W Forsberg ${ }^{2,3}$, Jack Goldberg ${ }^{2,3}$, Nicholas L Smith ${ }^{2,3}$ and Viola Vaccarino ${ }^{4}$
}

\begin{abstract}
Background: Atherosclerosis is a complex process involving both genetic and epigenetic factors. The monoamine oxidase A (MAOA) gene regulates the metabolism of key neurotransmitters and has been associated with cardiovascular risk factors. This study investigates whether MAOA promoter methylation is associated with atherosclerosis, and whether this association is confounded by familial factors in a monozygotic (MZ) twin sample.

Methods: We studied 84 monozygotic (MZ) twin pairs drawn from the Vietnam Era Twin Registry. Carotid intima-media thickness (IMT) was measured by ultrasound. DNA methylation in the MAOA promoter region was quantified by bisulfite pyrosequencing using genomic DNA isolated from peripheral blood leukocytes. The association between DNA methylation and IMT was first examined by generalized estimating equation, followed by matched pair analyses to determine whether the association was confounded by familial factors.

Results: When twins were analyzed as individuals, increased methylation level was associated with decreased IMT at four of the seven studied $\mathrm{CpG}$ sites. However, this association substantially reduced in the matched pair analyses. Further adjustment for MAOA genotype also considerably attenuated this association.

Conclusions: The association between MAOA promoter methylation and carotid IMT is largely explained by familial factors shared by the twins. Because twins reared together share early life experience, which may leave a long-lasting epigenetic mark, aberrant MAOA methylation may represent an early biomarker for unhealthy familial environment. Clarification of familial factors associated with DNA methylation and early atherosclerosis will provide important information to uncover clinical correlates of disease.
\end{abstract}

Keywords: DNA methylation, MAOA, Carotid atherosclerosis, Monozygotic twins, Familial factors

\section{Background}

Atherosclerosis is a complex process resulting from the interaction between genetic and non-genetic factors. Despite substantial effort, our understanding of atherosclerosis remains incomplete. Epigenetic modifications, especially DNA methylation, represent an attractive molecular mechanism for atherosclerosis because they may be altered in response to environmental exposures and lifestyle interventions [1]. Indeed, studies in both human $[2,3]$ and animals $[4,5]$ have reported associations of DNA methylation variation with subclinical atherosclerosis and

\footnotetext{
* Correspondence: jzhao5@tulane.edu

'Department of Epidemiology, School of Public Health and Tropical

Medicine, Tulane University, New Orleans, LA, USA

Full list of author information is available at the end of the article
}

atherosclerotic cardiovascular disease (CVD). However, specific genes and the epigenetic pathways underlying atherosclerosis remain largely uncharacterized.

Monoamine oxidase A (MAOA), encoded by the $\mathrm{X}$ chromosome, catalyzes the oxidative deamination of biogenic amines, such as serotonin, dopamine and norepinephrine, and plays a critical role in maintaining the metabolic homeostasis of neurotransmitters. Abnormal MAOA activity has been implicated in several neuropsychiatric disorders [6], and recently pancreatic beta cell function [7] and glucose metabolism [8]. A variable number of tandem repeats (VNTR) of a 30-bp sequence located approximately $1.2 \mathrm{~kb}$ upstream of the coding region [9], termed MAOA-uVNTR, has been associated with psychiatric/behavioral disorders $[10,11]$ and

\section{Biomed Central}


cardiovascular risk factors, including body mass index [12], obesity [13], and lipid levels [14]. However, a recent study failed to detect a relationship between an individual's brain $M A O A$ level and $M A O A$ genotype [15], suggesting that there are additional regulatory mechanisms that control the expression of $M A O A$ gene.

The purpose of this study is to investigate the association between DNA methylation variation in the MAOA promoter region and carotid atherosclerosis, assessed by common carotid intima-media thickness (IMT), using a monozygotic co-twin control design. Because both epigenetic variation [16] and carotid atherosclerosis [17] are under genetic control, it is critical to take into account any potential shared genetic influences between DNA methylation and atherosclerosis. In addition, it is important to control for early family environment because epigenetic variation is influenced by early life experience, which may leave long-lasting epigenetic marks on the epigenome that will likely affect cardiometabolic risk later in life $[18,19]$. A monozygotic co-twin control design controls for shared genes and early family environment, thus represents a useful model for epigenetic research of complex traits such as atherosclerosis. As far as we are aware, this is the first study to examine the association between $M A O A$ gene methylation and subclinical cardiovascular disease, and the potential impact of familial factors on this association in a well-matched monozygotic twin sample.

\section{Methods}

\section{Study population}

Twins included in this study were drawn from the Vietnam Era Twin (VET) Registry, one of the largest twin registries in the U.S. [20] All twins were male veterans who were born between 1946 and 1956. A total of 307 twin pairs (who were raised in the same household) were recruited by the Emory Twin Studies (ETS), which included two companion studies to investigate the role of psychological, behavioral, and biological risk factors for subclinical cardiovascular disease in twins. The ETS include male-male twin pairs, including 187 monozygotic (MZ) pairs and 120 dizygotic (DZ) pairs, with an inclusion of two samples of twin pairs discordant for major depression or posttraumatic stress disorder (PTSD). The ETS protocol has been described elsewhere [21]. This research was approved by the Emory Institutional Review Board, and all twins signed an informed consent.

The current analysis included 84 monozygotic twin pairs from the ETS. These twin pairs were selected based on the availability of DNA samples and phenotype data for both members of a twin pair. All twins were examined in pairs at the Emory University General Clinical Research Center between 2002 and 2010, where their medical history was updated. All twins were Caucasian. Zygosity information was determined by DNA analysis.

\section{Risk factor measurements}

All measurements were performed in the morning after an overnight fast, and both members of a pair were tested at the same time. A medical history and a physical exam were obtained from all twins. Body mass index (BMI) was calculated by dividing weight in kilograms by the square of height in meters. Cigarette smoking was classified into current smoker (any number of cigarettes) versus never or past smoker. Pack-years of smoking were calculated as the number of packs of cigarettes smoked per day times the number of years smoked. Physical activity was assessed by means of a modified version of the Baecke Questionnaire of Habitual Physical Activity used in the Atherosclerosis Risk in Communities (ARIC) Study [22], a 16-question instrument documenting level of physical activity at work, during sports and nonsports activities. The total physical activity score was used in the analysis. Information on alcohol consumption was collected by asking about the number of alcoholic drinks (beer, wine or liquor) consumed in a typical week. The total amount of alcohol consumption (in grams) per week was estimated based on the following algorithms: $4 \mathrm{oz}$ of wine contains $10.8 \mathrm{~g}, 12 \mathrm{oz}$ of beer contains $13.2 \mathrm{~g}$, and $1.5 \mathrm{oz}$ of liquor contains $15.1 \mathrm{~g}$ of ethanol. Hypertension was defined as systolic blood pressure $>140 \mathrm{mmHG}$ or diastolic blood pressure $>90 \mathrm{mmHg}$. Diabetes was defined as fasting blood glucose $>126 \mathrm{mg} / \mathrm{dL}(7.0 \mathrm{mmol} / \mathrm{L})$.

\section{Carotid intima-media thickness (IMT) measurement}

Common carotid artery IMT was measured using high resolution B-mode ultrasonography by standard techniques [23]. Briefly, IMT was quantified both on the near and far wall at the distal $1.0 \mathrm{~cm}$ of the left and right common carotid arteries proximal to the bifurcation. For each segment, the sonographer used multiple different scanning angles to identify the longitudinal image of IMT showing the maximum IMT. At least 10 pictures for each segment were stored digitally, and measurements were made off-line using semi-automated computerized analytical software (Carotid Tools, MIA Inc., Iowa City, Iowa) by one observer blinded to other twin data. Of the stored images, the one with maximum thickness was selected, and IMT measured, for each segment. Average values of the IMT of each of the four segments (right near and far walls, and left near and far walls) were used as the IMT values for each twin in the analysis (total mean of maximum IMT). In order to minimize error, the same technician did IMT measurements throughout the study, and the same equipment 
and analytical software was used to measure IMT for all the twin participants. In our lab, the mean absolute difference in IMT measured in 7 subjects in whom 2 carotid artery examinations were performed 3 days apart, was $0.03( \pm 0.02) \mathrm{mm}$. The mean difference in 2 successive readings of the same 10 segments of common carotid IMT was $0.02( \pm 0.02) \mathrm{mm}$ with a Pearson correlation coefficient of 0.93 .

\section{DNA methylation analyses by quantitative bisulfite pyrosequencing}

Genomic DNA was isolated from peripheral blood leukocytes by standard method. DNA methylation level in the MAOA gene promoter region was determined using quantitative bisulfite pyrosequencing by the EpigenDx Inc (Worcester, MA), a company specializing in epigenetic analysis by pyrosequencing. Briefly, the human MAOA promoter methylation assay covered seven $\mathrm{CpG}$ dinucleotides in the promoter region ranging from -749 base pair (bp) to $-675 \mathrm{bp}$ from the transcriptional start site (TSS), based on Ensembl Gene ID ENSG00000189221 and the Transcript ID ENST00000338702. To sequence these selected $\mathrm{CpG}$ sites, we designed one pyrosequencing assay and tested for PCR preferential amplification and quantitative pyrosequencing analysis. Figure 1 schematically illustrates the target $\mathrm{CpG}$ sites by pyrosequencing assay with respect to transcription start site (TSS) and the MAOA-uVNTR polymorphism.

The bisulfite conversion was performed with $500 \mathrm{ng}$ genomic DNA using the EZ DNA methylation kit (ZymoResearch, Inc., CA). The PCR reaction was performed with $0.2 \mu \mathrm{M}$ of each primer with one of the PCR primers being biotinylated to purify the final PCR product using Sepharose beads. The PCR product was bound to Streptavidin Sepharose HP (Amersham Biosciences, Uppsala, Sweden), and the Sepharose beads containing the immobilized PCR product were purified, washed and denatured using $0.2 \mathrm{M} \mathrm{NaOH}$ solution and rewashed using the Pyrosequencing Vacuum Prep Tool (Pyrosequencing, Qiagen) as recommended by the manufacturer. Then $0.5 \mu \mathrm{M}$ Pyrosequencing primer was annealed to the purified single-stranded PCR product. $10 \mu \mathrm{l}$ of the PCR products were sequenced by Pyrosequencing PSQ96 HS System (Pyrosequencing, Qiagen) following the manufacturer's instructions (Pyrosequencing, Qiagen). The methylation status of each $\mathrm{CpG}$ site was analyzed individually as an artificial T/C SNP using QCpG software (Pyrosequencing, Qiagen). Methylation level at each CpG site was calculated as the percentage of the methylated alleles over the sum of methylated and unmethylated alleles. The mean methylation level was calculated using methylation levels of all measured CpG sites within the targeted region of the gene. Pyrosequencing assay was done on duplicate samples, with a correlation of over $99.8 \%$ between the two runs for a same sample. For quality control, each experiment included non-CpG cytosines as internal controls to verify efficient sodium bisulfite DNA conversion. We also included unmethylated and methylated DNAs as controls in each run. In addition, we performed PCR bias testing using Pyrosequencing by mixing the unmethylated DNA control and in vitro methylated DNA at different ratios $(0,20 \%, 40 \%$, up to $100 \%)$ followed by bisulfite modification, PCR and pyrosequencing analysis. The percent methylation obtained from the mixing study showed high correlation with expected methylation percentages with a correlation coefficient of 0.97 , indicating high quality methylation data.

\section{Genotyping of the MAOA-uVNTR variant}

To examine whether the association between MAOA methylation variation and IMT is modified by the MAOA-uVNTR, we genotyped the MAOA-uVNTR variant according to the method described previously [24]. In brief, genomic DNA was amplified with forward primer 5'-ACAGCCTGACCGTGGAGAAG - $-3^{\prime}$ (fluorescently

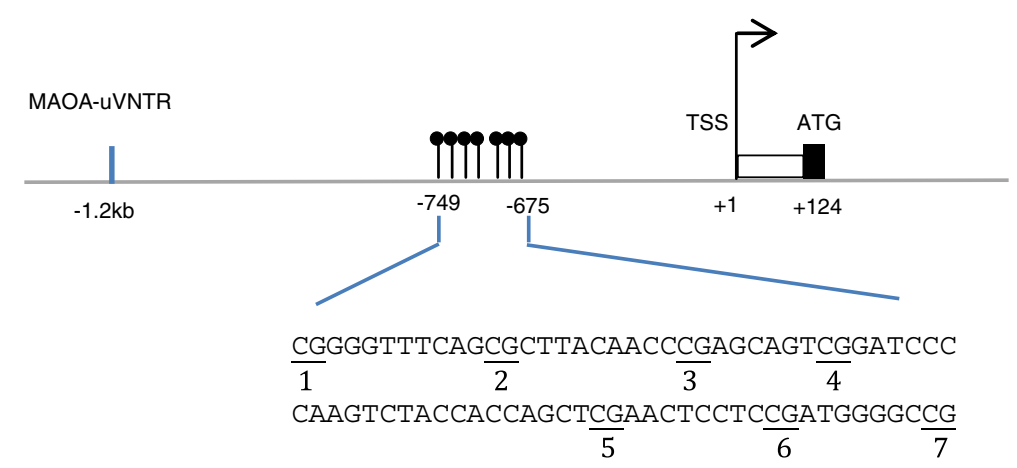

Figure $1 \mathrm{~A}$ schematic illustration for the $\mathrm{CpG}$ sites in a promoter region of MAOA gene assayed in this study in relation to the MAOA-uVNTR variant. The sequence shown represents a 75 bp fragment ( -749 to -675 with respect to TSS) in the $5^{\prime}$-UTR of MAOA. Numbers 1-7 refer to locations of the CpG sites assayed in this study. TSS: Transcriptional Start Site; ATG: Translational Start Codon. 
labeled with FAM) and reverse primer $5^{\prime}$ - GAACGGACGCTCCATTCGGA -3', with PCR thermal cycling conditions of 10 -min denaturation at $95^{\circ} \mathrm{C}$, then 35 cycles of $95^{\circ} \mathrm{C}$ for $30 \mathrm{sec}, 60^{\circ} \mathrm{C}$ for $30 \mathrm{sec}$ and $72^{\circ} \mathrm{C}$ for $1 \mathrm{~min}$. This was followed by 5 -min extension at $72^{\circ} \mathrm{C}$. Amplified PCR products were visualized on a capillary-based ABI3100 Genetic Analyzer along with GeneScan 500 ROX as sizing standard. Data collection and allele scoring was performed using GeneScan 3.7 and Genotyper 3.7 (Applied Biosystems). PCR products included 2 repeated sequences in 3 and 4 repeats.

\section{Statistical analyses}

Prior to analysis, continuous variables including IMT and methylation data were logarithmically transformed to improve normality. To adjust for multiple testing, we used the Benjamini-Hochberg false discovery rate (FDR) procedure [25] to correct for the number of CpG sites evaluated and used an FDR-adjusted $\mathrm{P}$ value (q value) threshold of 0.05 to determine statistical significance. The PROC MULTTEST procedure in SAS 9.2 was used to calculate the adjusted-FDR (the q-value method).

1) Regression analysis by treating twins as individuals: We examined the association of methylation level at each CpG site and the mean methylation level of all measured CpG sites with carotid IMT, adjusting for age, smoking, BMI, diabetes, HDL, LDL, systolic blood pressure, and physical activity level. These analyses were done using generalized estimating equation (GEE) models, in which carotid IMT was the dependent variable, DNA methylation level was the independent variable, and twin pair was included as a clustering variable to account for the within twin pair correlations.

2) Matched pair analyses by considering twins as members of a twin pair: To examine whether the association between DNA methylation and IMT was explained by shared genetic and/or familial environment, we conducted matched pair analysis by treating twins as members of a twin pair. First, we calculated the intrapair difference in DNA methylation level, defined as the difference in DNA methylation between two members of a twin pair. The intrapair differences in IMT and other continuous variables were similarly calculated. Then we conducted linear regression by regressing the intrapair difference in IMT (dependent variable) on the intrapair difference in methylation level (independent variable) at each CpG site, adjusting for intrapair differences in smoking (pack-year), BMI, HDL, LDL, systolic blood pressure and level of physical activity.
3) Sensitivity analyses: As described before, our sample included twins recruited by two projects with oversampling of twins with major depression or PTSD. To examine whether the oversampling scheme influences our results, we performed separate analyses by further adjusting for depressive symptoms (as measured by Beck Depressive Inventory scores) or PTSD ( $\mathrm{n}=35$ including 9 pairs and 17 singletons). To evaluate the potential impact of MAOA-uVNTR genotype on the association between methylation variation and IMT, we conducted separate analyses by further controlling for this genotype in statistical models. To determine whether combining data from the two studies has an impact on our results, we included study affiliation (THS or SAVEIT) as a covariate in the statistical analyses. In addition, we conducted sensitivity analysis to examine whether batch effects influence our results by including an indicator variable for sample batches (plate 1 vs. plate 2) in the statistical analysis.

\section{Results}

The age of the twins ranged from 48 to 61 years with a mean of 55. Twins included in the current analysis were not different from those not included in terms of IMT and other covariates. Table 1 presents the demographic characteristics of the twins included in this analysis.

The mean methylation level of the seven CpG sites examined in $M A O A$ promoter was $5.0 \%$, with the highest and lowest methylation levels occurring at CpG site $5(7.2 \%)$ and site 1 (3.7\%), respectively. Methylation levels of the seven CpG sites in MAOA promoter were highly correlated with each other (correlation ranges from 0.77 to 0.93 , all p's $<0.0001$ ). Carotid IMT was

Table 1 Demographic, clinical and laboratory characteristics of the twins

\begin{tabular}{ll}
\hline Variable & Mean \pm SD or \% \\
\hline Age (years) & $55.1 \pm 2.8$ \\
Type 2 diabetes (\%) & 11.4 \\
Hypertension (\%) & 36.5 \\
Current smoking (\%) & 37.6 \\
Body mass index (kg/m [2])) & $29.4 \pm 4.8$ \\
Systolic blood pressure (mmHg) & $129.3 \pm 17.5$ \\
Diastolic blood pressure (mmHg) & $81.4 \pm 11.6$ \\
High density lipoprotein cholesterol (mg/dL) & $37.6 \pm 10.7$ \\
Low density lipoprotein cholesterol (mg/dL) & $123.3 \pm 36.8$ \\
Total triglyceride (mg/dL) & $177.5 \pm 102.5$ \\
Total mean of maximum intima-media & $769.7 \pm 121.8$ \\
thickness ( $\mu$ m) & \\
Mean MAOA methylation level $(\%)$ & $5.0 \pm 1.6$ \\
\hline
\end{tabular}


negatively correlated with methylation variation at five of the seven studied CpG sites (Table 2). Mean MAOA promoter methylation was also inversely correlated with carotid IMT (correlation $=-0.17, \mathrm{p}=0.03$ ).

1) Results of multivariate GEE by treating twins as individuals: DNA methylation levels at four $\mathrm{CpG}$ sites in the MAOA promoter showed significant individual association with IMT after adjusting for known coronary risk factors (all p's $\leq 0.05$ ). The mean MAOA methylation level was also significantly associated with carotid IMT $(\mathrm{p}=0.02)$. On average, a $10 \%$ increase in the mean MAOA methylation level was associated with a decrease of $115 \mu \mathrm{m}$ (95\% CI: $36,195)$ in carotid IMT. In the multivariate GEE models, age $(\mathrm{p}=0.01)$ and systolic blood pressure $(\mathrm{p}=0.002)$ were also significantly and positively associated with carotid IMT. Further adjustment for the MAOA-uVNTR genotype attenuated the association between MAOA methylation and IMT. Results for multivariate GEE analyses are shown in Table 3.

2) Results by matched pair analyses: DNA methylation levels of the two members within a twin pair were highly correlated at each of the examined CpG site (all p's $<0.0001$ ). The mean methylation level of the twins within a pair was also significantly correlated $(\mathrm{r}=0.38, \mathrm{p}=0.0004)$. Regression analysis using intrapair differences demonstrated that methylation variation at none of the seven $\mathrm{CpG}$ sites was associated with IMT, suggesting that the association observed in individual analysis is largely explained by genetic similarity or other familial factors shared by the twins. Results for matched pair analyses are shown in Table 4.

3) Results for sensitivity analyses: Additional adjustment for depression or PTSD in matched pair analysis did not affect the association. Further

Table 2 Correlation between carotid IMT and MAOA promoter methylation variation

\begin{tabular}{lccc}
\hline Position & $\begin{array}{c}\text { Genomic } \\
\text { location }\end{array}$ & $\begin{array}{c}\text { Methylation } \\
\text { level }\end{array}$ & $\begin{array}{c}\text { Correlation } \\
\text { with IMT }\end{array}$ \\
\cline { 2 - 4 } & (Relative to TSS, bp) & (\%, mean \pm SD) & (P value) \\
\hline 1 & $43514718(-749)$ & $3.70 \pm 1.83$ & $-0.17(0.03)$ \\
2 & $43514729(-738)$ & $3.73 \pm 1.60$ & $-0.22(0.005)$ \\
3 & $43514740(-727)$ & $5.44 \pm 1.72$ & $-0.10(0.12)$ \\
4 & $43514748(-719)$ & $4.34 \pm 1.76$ & $-0.20(0.01)$ \\
5 & $43514773(-694)$ & $7.24 \pm 1.84$ & $-0.16(0.04)$ \\
6 & $43514782(-684)$ & $5.61 \pm 1.79$ & $-0.15(0.05)$ \\
7 & $43514791(-674)$ & $4.67 \pm 1.92$ & $-0.12(0.13)$ \\
Mean & & $4.96 \pm 1.65$ & $-0.17(0.03)$ \\
\hline
\end{tabular}

*On chromosome $\mathrm{X}$ according to GCRh37/hg19.
Table 3 Association between carotid IMT and MAOA methylation variation by multivariate GEE

\begin{tabular}{lccc}
\hline Position & $\boldsymbol{\beta}$ & $\mathbf{P}^{*}$ & $\mathbf{P}^{\mathbf{*}}$ \\
\hline 1 & -0.07 & 0.04 & 0.07 \\
2 & -0.08 & 0.02 & 0.03 \\
3 & -0.06 & 0.14 & 0.20 \\
4 & -0.06 & 0.05 & 0.08 \\
5 & -0.10 & 0.03 & 0.05 \\
6 & -0.06 & 0.15 & 0.23 \\
7 & -0.06 & 0.10 & 0.14 \\
Mean & -0.09 & 0.02 & 0.06 \\
\hline
\end{tabular}

B:regression coefficient; ${ }^{*} \mathrm{P}$ values adjusted for multiple testing and covariates, including age, smoking, BMI, diabetes, LDL, HDL, SBP and physical activity;

${ }^{\ddagger}$ Further adjusting for MAOA genotype.

adjustments of the study affiliation (THS or SAVEIT) or the MAOA-uVNTR genotype did not change our results.

\section{Discussion}

We found that DNA methylation variation in the MAOA promoter region is associated with carotid atherosclerosis when twins were treated as individuals, but the association substantially attenuated when twins were analyzed in pairs, a statistical method that effectively controls for genetic background (which is identical in MZ twins) and other familial factors. These results suggest that genetic predisposition and/or shared family environment could confound the relationship between MAOA promoter methylation and carotid atherosclerosis, or represent important antecedents to this association.

There are several ways through which familial factors may affect the relationship between DNA methylation and early atherosclerosis. First, there could be familial confounding factors. For example, children raised in families with low socio-economic status (SES) may have an increased risk of subsequent CVD [26,27], whereas early life socio-economic position is also associated with

Table 4 Results for matched pair analyses

\begin{tabular}{lcc}
\hline Position & $\boldsymbol{\beta}$ & $\mathbf{P}^{*}$ \\
\hline 1 & -0.002 & 0.67 \\
2 & -0.009 & 0.10 \\
3 & -0.001 & 0.89 \\
4 & -0.007 & 0.19 \\
5 & -0.003 & 0.42 \\
6 & -0.007 & 0.16 \\
7 & -0.006 & 0.16 \\
Mean & -0.005 & 0.27 \\
\hline Bregrion coefficing
\end{tabular}

B:regression coefficient; " Adjusted for intrapair differences in smoking (pack-years), BMI, LDL, HDL, blood pressure and physical activity. 
adult DNA methylation variation [28]. In our study, further adjustments for levels of education and socioeconomic status in adulthood did not affect the relationship between MAOA methylation and IMT. While childhood socioeconomic indicators were not available in our sample, these familial factors were accounted for in the matched pair analyses because twins were raised in the same family during childhood. Because the association between MAOA methylation and IMT substantially reduced after accounting for familial factors, our findings indicate that factors shared by the twins (genetic, parental, maternal, and/or other familial environment) may be important in the link between MAOA methylation variation and atherosclerosis. Second, familial factors may be necessary antecedents to epigenetic alterations or subclinical atherosclerosis $[29,30]$. Because monozygotic twins are matched on genetic and/or early life family environment, our pairwise analysis effectively controls for these factors.

Recent studies in monozygotic twins have reported associations between DNA methylation variation and human diseases, such as type 1 diabetes [31], psychotic disorders [32,33] and systemic lupus erythematosus [34], indicating that epigenetic variability may contribute to phenotypic discordance between genetically identical individuals [35,36]. Our group also reported associations between global DNA methylation and insulin resistance [37], and between serotonin transporter gene (SLC6A4) promoter methylation and obesity measures [38] in this same monozygotic twin sample. The familial confounding identified in this study, however, does not contradict previous findings. First, monozygotic twins may not be exactly identical [39] and stochastic origins of DNA methylation variation are possible in $\mathrm{MZ}$ twins. The two members of a monozygotic pair may harbor subtle genetic differences, such as copy number variation [39], that are associated with an increased level of epigenetic stochasticity. Indeed, a recent large-scale DNA methylation profiling in twins indicates that stochastic epigenetic variation may be more common than we previously appreciated [40]. Second, environment exposed to the two identical twins may not be exactly the same, and environment unique to each member, e.g., disparity in placenta blood supply, may induce epigenetic variation that could potentially increase disease risk. Third, the familial confounding found in this study may represent a disease- and/or gene-specific phenomenon, but not representing the case of other diseases or genes.

In this study, we observed that DNA methylation at particular $\mathrm{CpG}$ sites showed considerable variability within monozygotic twin pairs (intrapair difference ranges from -0.08 to -0.24$)$. This agrees with findings by other investigators [31,32]. In addition, the magnitude of DNA methylation variation is relatively small compared to DNA methylation alterations generally observed in cancer. However, the magnitude of methylation variation in our study is comparable to many of the previous studies on nonmalignant complex disorders [31,34,38,40-44]. It is possible that epigenetic variation at multiple $\mathrm{CpG}$ sites may be involved in the pathogenesis of complex disease, but each individually confers only a small risk effect to disease. This observation most likely reflects the norm for most human complex disorders and parallels with findings from genome-wide association studies in which many genetic variants contribute to disease risk but the predicted risk associated with each variant is generally small.

A previous study has shown that smoking is closely related to MAOA activity and may also influence $M A O A$ promoter methylation [45]. In this study, however, we did not find a relationship between smoking status and methylation level at any of the examined CpG sites. This may reflect a site-specific epigenetic effect on smoking because the two studies examined different CpG sites in the MAOA promoter region ( 39kb apart). The lack of association between MAOA methylation and smoking may also be due to low statistical power of our analysis. However, to our best knowledge, the use of 84 monozygotic twin pairs in our study represents one of the largest epigenetic twin studies performed for any complex disease phenotype to date.

Our study has a number of limitations that should be considered when interpreting the data presented here. First, because of practical difficulties in obtaining coronary artery tissues from living individuals, methylation levels were tested in peripheral blood leukocytes, but not directly from arteries or atherosclerotic tissues. Therefore, our results may not provide a direct index of methylation in the vascular system. In addition, our epigenetic data were collected from DNA derived from whole blood leukocytes, which includes a heterogeneous mixture of cell types; as such, we were unable to assess methylation status specific to blood cells. Second, our sample included twins with oversampling of either major depression or PTSD, both of which may influence CVD risk. However, the observed associations between aberrant DNA methylation and subclinical CVD are unlikely to be confounded by depression or PTSD because further adjustment for these two psychiatric conditions did not change the results. Third, DNA methylation influences disease risk through regulating gene expression, which could not be evaluated in our study due to lack of fresh leukocytes or atherosclerotic tissues. Additionally, we could not assess the relationship between DNA methylation and platelets MAOA activity due to lack of platelets samples for the twins. The association of DNA methylation with MAOA gene expression should be investigated in future study. Fourth, we only focused on a small region in the promoter of MAOA gene, whereas 
epigenetic variation in other genomic regions may also influence disease susceptibility. These regions should be examined in future research. Fifth, our sample size is relatively small which may potentially limit our power in detecting the shared familial factors. However, to the best of our knowledge, a sample size of 84 monozygotic twin pairs represents the largest possible sample size for a matched co-twin control analysis. Finally, our twin sample was derived from a middle-aged sample of male military veterans; therefore, the generalizability to females and other younger or older populations is unknown.

\section{Conclusions}

In summary, in a matched monozygotic twin sample, we found that the association between MAOA promoter methylation and carotid atherosclerosis is largely explained by genetic predisposition and/or family environment shared by the twins. Familial factors, e.g., genetic, parental nutrition, maternal care, and other familial environment, may be a key element that could potentially increase future risk of atherosclerosis through the epigenome. Disentangling epigenetic effects from the confounding influences of genetic and/or familial environmental heterogeneity is critical in elucidating the etiological role of epigenetic variation in disease development and may also provide important information to uncover clinical correlates of disease.

\section{Competing interest}

All authors declared that they have no competing interest.

\section{Authors' contributions}

JZ conceived the study, conducted the statistical analyses and wrote the manuscript. CWF conducted the statistical analyses. JG, NLS and W contributed to discussion, interpreted the study findings and revised/edited the manuscript. All authors read and approved the final manuscript.

\section{Acknowledgements}

The United States Department of Veterans Affairs has provided financial support for the development and maintenance of the Vietnam Era Twin (VET) Registry. Numerous organizations have provided invaluable assistance in the conduct of this study, including: Department of Defense; National Personnel Records Center, National Archives and Records Administration; the Internal Revenue Service; National Institutes of Health; National Opinion Research Center; National Research Council, National Academy of Sciences; the Institute for Survey Research, Temple University. Most importantly, the authors gratefully acknowledge the continued cooperation and participation of the members of the VET Registry and their families. Without their contribution this research would not have been possible.

\section{Funding}

This study was supported by grant 0730100N from the American Heart Association, grants R21HL092363, K01AG034259, R01DK091369, R01HL68630 and R01AG026255 from the NIH.

\section{Author details}

${ }^{1}$ Department of Epidemiology, School of Public Health and Tropical Medicine, Tulane University, New Orleans, LA, USA. ${ }^{2}$ Seattle Epidemiologic Research \& Information Center, Veterans Affairs Office of Research \& Development, Seattle, WA, USA. ${ }^{3}$ Department of Epidemiology, University of
Washington, Seattle, WA, USA. ${ }^{4}$ Department of Epidemiology, Emory University School of Public Health, Atlanta, GA, USA.

Received: 1 June 2012 Accepted: 31 October 2012 Published: 2 November 2012

\section{References}

1. Wierda RJ, Geutskens SB, Jukema JW, Quax PH, van den Elsen PJ: Epigenetics in atherosclerosis and inflammation. J Cell Mol Med 2010, 14:1225-1240.

2. Kim M, Long TI, Arakawa K, Wang R, Yu MC, Laird PW: DNA methylation as a biomarker for cardiovascular disease risk. PLOS One 2010, 5:e9692.

3. Movassagh M, Choy MK, Goddard M, Bennett MR, Down TA, Foo RS: Differential DNA methylation correlates with differential expression of angiogenic factors in human heart failure. PLoS One 2010, 5:e8564.

4. Chen Z, Karaplis AC, Ackerman SL, Pogribny IP, Melnyk S, Lussier-Cacan S, Chen MF, Pai A, John SW, Smith RS, Bottiglieri T, Bagley P, Selhub J, Rudnicki MA, James SJ, Rozen R: Mice deficient in methylenetetrahydrofolate reductase exhibit hyperhomocysteinemia and decreased methylation capacity, with neuropathology and aortic lipid deposition. Hum Mol Genet 2001, 10:433-443.

5. Lund G, Andersson L, Lauria M, Lindholm M, Fraga MF, Villar-Garea A Ballestar E, Esteller M, Zaina S: DNA methylation polymorphisms precede any histological sign of atherosclerosis in mice lacking apolipoprotein e. J Biol Chem 2004, 279:29147-29154.

6. Shih JC, Chen K, Ridd MJ: Role of mao $a$ and $b$ in neurotransmitter metabolism and behavior. Pol J Pharmacol 1999, 51:25-29.

7. Adeghate $\mathrm{E}$, Parvez $\mathrm{H}$ : The effect of diabetes mellitus on the morphology and physiology of monoamine oxidase in the pancreas. NeuroToxicology 2004, 25:167-173.

8. Panagiotidis G, Lindstrom P, Stenstrom A, Lundquist I: Glucose modulation of islet monoamine oxidase activity in lean and obese hyperglycemic mice. Metabolism 1993, 42:1398-1404.

9. Sabol SZ, Hu S, Hamer D: A functional polymorphism in the monoamine oxidase a gene promoter. Hum Genet 1998, 103:273-279.

10. Shih JC, Thompson RF: Monoamine oxidase in neuropsychiatry and behavior. Am J Hum Genet 1999, 65:593-598.

11. Shih JC, Chen K, Ridd MJ: Monoamine oxidase: From genes to behavior. Annu Rev Neurosci 1999, 22:197-217.

12. Camarena B, Santiago H, Aguilar A, Ruvinskis E, Gonzalez-Barranco J, Nicolini $\mathrm{H}$ : Family-based association study between the monoamine oxidase a gene and obesity: Implications for psychopharmacogenetic studies. Neuropsychobiology 2004, 49:126-129.

13. Need AC, Ahmadi KR, Spector TD, Goldstein DB: Obesity is associated with genetic variants that alter dopamine availability. Ann Hum Genet 2006, 70:293-303.

14. Brummett BH, Boyle SH, Siegler IC, Zuchner S, Ashley-Koch A, Williams RB: Lipid levels are associated with a regulatory polymorphism of the monoamine oxidase-a gene promoter (maoa-uvntr). Med Sci Monit 2008, 14:CR57-CR61.

15. Fowler JS, Alia-Klein N, Kriplani A, Logan J, Williams B, Zhu W, Craig IW, Telang F, Goldstein R, Volkow ND, Vaska P, Wang GJ: Evidence that brain mao a activity does not correspond to mao a genotype in healthy male subjects. Biol Psychiatry 2007, 62:355-358.

16. Daxinger $L$, Whitelaw E: Transgenerational epigenetic inheritance: More questions than answers. Genome Res 2010, 20:1623-1628.

17. Zhao J, Cheema FA, Bremner JD, Goldberg J, Su S, Snieder H, Maisano C, Jones L, Javed F, Murrah N, Le NA, Vaccarino V: Heritability of carotid intima-media thickness: A twin study. Atherosclerosis 2008, 197:814-820.

18. Lillycrop KA, Burdge GC: Epigenetic changes in early life and future risk of obesity. Int J Obes (Lond) 2011, 35:72-83.

19. Low FM, Gluckman PD, Hanson MA: Developmental plasticity and epigenetic mechanisms underpinning metabolic and cardiovascular diseases. Epigenomics. 2011, 3:279-294.

20. Goldberg J, Curran B, Vitek ME, Henderson WG, Boyko EJ: The vietnam era twin registry. Twin Res 2002, 5:476-481.

21. Shah AJ, Su S, Veledar E, Bremner JD, Goldstein FC, Lampert R, Goldberg J, Vaccarino $\mathrm{V}$ : Is heart rate variability related to memory performance in middle-aged men? Psychosom Med 2011, 73:475-482.

22. Richardson MT, Ainsworth BE, Wu HC, Jacobs DR Jr, Leon AS: Ability of the atherosclerosis risk in communities (aric)/baecke questionnaire to assess leisure-time physical activity. Int J Epidemiol 1995, 24:685-693. 
23. Simon A, Gariepy J, Chironi G, Megnien JL, Levenson J: Intima-media thickness: A new tool for diagnosis and treatment of cardiovascular risk. J Hypertens 2002, 20:159-169.

24. Haberstick BC, Lessem JM, Hopfer CJ, Smolen A, Ehringer MA, Timberlake D, Hewitt JK: Monoamine oxidase a (maoa) and antisocial behaviors in the presence of childhood and adolescent maltreatment. Am J Med Genet B Neuropsychiatr Genet 2005, 135B:59-64.

25. Benjamin $Y$, Hochberg $Y$ : Controlling the false discovery rate: A practical and powerful approach to multiple testing. Journal of the Royal Statistical Society. Series B (Methodological) 1995, 57:289-300.

26. Heim C, Binder EB: Current research trends in early life stress and depression: Review of human studies on sensitive periods, gene-environment interactions, and epigenetics. Exp Neurol 2012, 233:102-111.

27. Kittleson MM, Meoni LA, Wang NY, Chu AY, Ford DE, Klag MJ: Association of childhood socioeconomic status with subsequent coronary heart disease in physicians. Arch Intern Med 2006, 166:2356-2361.

28. Borghol N, Suderman M, McArdle W, Racine A, Hallett M, Pembrey M, Hertzman C, Power C, Szyf M: Associations with early-life socio-economic position in adult DNA methylation. Int J Epidemiol 2012, 41(1):62-74.

29. Harrap SB, Stebbing M, Hopper JL, Hoang HN, Giles GG: Familial patterns of covariation for cardiovascular risk factors in adults: The victorian family heart study. Am J Epidemiol 2000, 152:704-715.

30. Gluckman PD: Epigenetics and metabolism in 2011: Epigenetics, the life-course and metabolic disease. Nat Rev Endocrinol 2011, 8:74-76.

31. Rakyan VK, Beyan H, Down TA, Hawa MI, Maslau S, Aden D, Daunay A, Busato F, Mein CA, Manfras B, Dias KR, Bell CG, Tost J, Boehm BO, Beck S, Leslie RD: Identification of type 1 diabetes-associated DNA methylation variable positions that precede disease diagnosis. PLoS Genet 2011, 7: e1002300

32. Dempster EL, Pidsley R, Schalkwyk LC, Owens S, Georgiades A, Kane F, Kalidindi S, Picchioni M, Kravariti E, Toulopoulou T, Murray RM, Mill J: Disease-associated epigenetic changes in monozygotic twins discordant for schizophrenia and bipolar disorder. Hum Mol Genet 2011, 20:4786-4796.

33. Mill J, Tang $T$, Kaminsky Z, Khare $T$, Yazdanpanah $S$, Bouchard $L$, Jia $P$, Assadzadeh A, Flanagan J, Schumacher A, Wang SC, Petronis A: Epigenomic profiling reveals DNA-methylation changes associated with major psychosis. Am J Hum Genet 2008, 82:696-711.

34. Javierre BM, Fernandez AF, Richter J, Al-Shahrour F, Martin-Subero الر, Rodriguez-Ubreva J, Berdasco M, Fraga MF, O'Hanlon TP, Rider LG, Jacinto FV, Lopez-Longo FJ, Dopazo J, Forn M, Peinado MA, Carreno L, Sawalha AH, Harley JB, Siebert R, Esteller M, Miller FW, Ballestar E: Changes in the pattern of DNA methylation associate with twin discordance in systemic lupus erythematosus. Genome Res 2010, 20:170-179.

35. Mill J, Dempster E, Caspi A, Williams B, Moffitt T, Craig I: Evidence for monozygotic twin $(\mathrm{mz})$ discordance in methylation level at two cpg sites in the promoter region of the catechol-o-methyltransferase (comt) gene. Am J Med Genet B Neuropsychiatr Genet 2006, 141B:421-425.

36. Bell JT, Saffery R: The value of twins in epigenetic epidemiology. Int J Epidemiol 2012, 41(1):140-150.

37. Zhao J, Goldberg J, Bremner JD, Vaccarino V: Global DNA methylation is associated with insulin resistance: A monozygotic twin study. Diabetes 2012, 61:542-546.

38. Zhao J, Goldberg J, Vaccarino V: Promoter methylation of serotonin transporter gene is associated with obesity measures: A monozygotic twin study. Int J Obes (Lond) 2012, 10.1038/ijo.2012.8.

39. Silva S, Martins Y, Matias A, Blickstein I: Why are monozygotic twins different? J Perinat Med 2011, 39:195-202.

40. Kaminsky ZA, Tang T, Wang SC, Ptak C, Oh GH, Wong AH, Feldcamp LA, Virtanen C, Halfvarson J, Tysk C, McRae AF, Visscher PM, Montgomery GW, Gottesman II, Martin NG, Petronis A: DNA methylation profiles in monozygotic and dizygotic twins. Nat Genet 2009, 41:240-245.

41. Nguyen A, Rauch TA, Pfeifer GP, Hu WW: Global methylation profiling of lymphoblastoid cell lines reveals epigenetic contributions to autism spectrum disorders and a novel autism candidate gene, rora, whose protein product is reduced in autistic brain. FASEB J 2010, 24:3036-3051.

42. Feinberg AP, Irizarry RA, Fradin D, Aryee MJ, Murakami $P$, Aspelund $T$, Eiriksdottir G, Harris TB, Launer L, Gudnason V, Fallin MD: Personalized epigenomic signatures that are stable over time and covary with body mass index. Sci Transl Med 2010, 2:49ra67.
43. Bell CG, Teschendorff AE, Rakyan VK, Maxwell AP, Beck S, Savage DA: Genome-wide DNA methylation analysis for diabetic nephropathy in type 1 diabetes mellitus. BMC Med Genomics 2010, 3:33.

44. Bell CG, Finer S, Lindgren CM, Wilson GA, Rakyan VK, Teschendorff AE, Akan P, Stupka E, Down TA, Prokopenko I, Morison IM, Mill J, Pidsley R, Deloukas P, Frayling TM, Hattersley AT, McCarthy MI, Beck S, Hitman GA: Integrated genetic and epigenetic analysis identifies haplotype-specific methylation in the fto type 2 diabetes and obesity susceptibility locus. PLoS One 2010, 5:e14040.

45. Philibert RA, Beach SR, Gunter TD, Brody GH, Madan A, Gerrard M: The effect of smoking on maoa promoter methylation in DNA prepared from lymphoblasts and whole blood. Am J Med Genet B Neuropsychiatr Genet 2010, 153B:619-628.

doi:10.1186/1471-2350-13-100

Cite this article as: Zhao et al:: MAOA promoter methylation and susceptibility to carotid atherosclerosis: role of familial factors in a monozygotic twin sample. BMC Medical Genetics 2012 13:100.

\section{Submit your next manuscript to BioMed Central and take full advantage of:}

- Convenient online submission

- Thorough peer review

- No space constraints or color figure charges

- Immediate publication on acceptance

- Inclusion in PubMed, CAS, Scopus and Google Scholar

- Research which is freely available for redistribution

Submit your manuscript at www.biomedcentral.com/submit
C) Biomed Central 